\title{
THE ROLE OF INTERNAL CONTROL IN MANAGING THE RISKS SPECIFIC TO THE FINANCIAL FIELD
}

\author{
Valentin PÎRVUȚ \\ "Nicolae Bălcescu" Land Forces Academy, Sibiu, Romania \\ pirvut_v@yahoo.com
}

\begin{abstract}
This article deals with a currently discussed topic, namely that of preventive financial control, a concept that has to ensure a reasonable use of public funds in a transparent, economical, efficient and effective manner. In this sense the issues related to public internal financial control are considered instruments that actively influence the organizational and managerial culture of the public entity in a positive manner by engaging in control actions that are meant to identify and stop the possible illegal activities or actions, fraudulent or uneconomical use of public funds. I further detail the concept of public financial control with the two principal branches, that is the preventive financial control and the preventive financial control proper. The preventive financial control proper, by exercising the control visa for every financial supporting document affecting public funds, is a cornerstone regarding the exercise of financial control activity.
\end{abstract}

Keywords: strategy of public internal control, internal control, internal control standards, preventive financial control, credit officer

\section{Introduction}

The most important purpose of public institutions is to meet and satisfy the necessities and objectives of public and national interest in terms of transparency, efficiency and effectiveness. The continuous improvement of the establishment and use of public funds is required by mandatory legal provisions and the verification of compliance with all the laws is guaranteed by the control function.

By virtue of this principle, Romania through the Ministry of Finance - authority which has responsibility for policy formulation and implementation of financial control and financial management - implemented a public internal financial control system.

\section{The strategy of developing public internal control}

The first "Strategy of public internal financial control" appeared in Romania in
2001, on the European Commission recommendation, being updated constantly according to the evolving economic environment. This document is achieved by consulting and co-operating with the main stakeholders in the process control, such as: Ministry of Finance, Court of Auditors, the ministries with large budgets, structures exercising audit, academic structures, economic research institutes and specialists in the field.

The purpose of the PIFC Strategy is to establish the short- and medium-term strategic development of public internal financial control in Romania in the 20142016 period.

The development and modernization of public internal financial control in Romania involved the monitoring and verification of the following indicators [1]:

a) public revenues (establishment, registration and tracking receipts); 
b) public expenditure (management and use of funds for financing the expenditure in the established budgets;

c) the management of public external reimbursable and non-reimbursable funds;

d) revenues and expenses of national societies and companies in which the state is a majority shareholder.

The PIFC strategy's objective is to present the current state of PIFC as a result of the progress made in the last three years on the basis of the diagnostic analysis and the main lines of action.

\section{Internal control}

Respecting art. 5 para 2 of the Government Ordinance no. 119/1999 on internal/managerial control and preventive financial control, republished, with subsequent amendments, the Secretariat General of the Government issued the Order no. 400/2015 for approving the Code of internal managerial control of public entities comprising the internal control standards in public entities and the regulations on the duties and responsibilities of managers.

The Code of internal control comes in the form of internal control standards, which represent an important aid for managers in the knowledge of the general principles of good practice in terms of establishing general objectives by reference to a reference system and identification of a minimum set of management rules. In terms of forms, internal control can manifest through self-control, chain control, hierarchical control, and depending on the time of exercise, it may be ex-ante (before), concomitantly (in kind), ex-post (after) the operations subjected to control.

This code created the general manager's responsibility of deciding on the control measures required for the implementation and development of its internal control system, taking into account the specificities of the institution he leads and the internal control standards.
They also empower other persons occupying management positions, who are specialized in the implementation and development of operational procedures at their specific level of responsibility, punctual inspections and the organization of control activities through teams and specialized committees, depending on the identified activities and risks, resolving the observed failures or irregularities and reducing or maintaining an acceptable level of risk.

Through this delegation of responsibility which also means total involvement in organizing a control system most efficiently, managers have the legal mechanism and instrument to organize and implement their own system of internal control, not needing to wait for someone from outside to organize the control system. The actual control activities may include: observation, endorsement, approval, decision, resolution, decision, resolve, planning, verification, analysis, separation of duties, reporting and monitoring.

\section{Public internal financial control (PIFC)}

The purpose of the public internal financial control is to verify the legality and regularity of the operations, identify the weaknesses of the internal control system which allowed the fraud or improper management, as well as to propose measures to remedy them.

The public internal financial control includes:

1. Internal/managerial control has the following objectives:

- proper performance of the duties of public institutions, in terms of regularity, efficiency, economy and efficiency;

- protecting public funds against losses, waste, abuse or fraud;

- compliance with applicable laws.

2. Public internal audit is part of the internal/managerial control and it is organized under the direct leadership of the public entity [2]. 
3. Coordination and centralized harmonization of the system of internal/ managerial control and internal audit is ensured by the Ministry of Finance, through two premises:

- Central Harmonization Unit for Public Internal Audit - ensures the coordination, supervision and internal audit in the public sector;

- Central Harmonization Unit of Financial Management and Control Systems ensures the coordination and monitoring of the implementation and development of the internal/managerial control.

Those responsible for the design and development of internal/managerial control systems (i.e. ensuring functionally independent internal audit) are the managers of public entities.

\section{Preventive financial control}

The public entities are subject to preventive financial control by checking the legality and regularity of projects or operations aimed at: legal commitments (control of legal base), global and individual budget commitments (compliance control), budget appropriations employed (employment within budget appropriations), opening and allocation of budgetary appropriations, authorization of expenditure, payments and cash receipts, public revenues and establishment of marketable debt, reduction or cancellation of debt, recovery of paid or provided unduly amounts, sale, lease or rental of goods from private or public state domain and other operations established by order of Minister of public finance [3].

Organization of preventive financial control

The financial control proper can be applied to all public entities and to all financial operations, while the preventive financial control is delegated to the main credit officers through controllers delegated by the Ministry of Public Finance.

In the long-term, preventive financial control should be integrated in the sphere of managerial control, as this control will eliminate the risks in managing public funds.

Organization of preventive financial control proper

The authorised officers are obliged to organize preventive financial control proper and

to keep records, updating and reporting according to the methodological norms and commitments through financial-accounting divisions.

The head of the financial-accounting compartment establishes the projects of operations subjected to preventive financial control, the supporting documents and their circuit, respecting the legal provisions and submits them for approval to the entity head.

The preventive financial control proper is exercised by applying the personal seal with the visa of preventive financial control, by people with specialized professional skills within the accounting departments and in the financial limits for exercising control. The appointment, dismissal or change of personnel responsible for the PFC visa is done at the proposal of the entity leader with the approval of the superior entity, the respective persons not being entitled to initiate the transaction subjected to the visa.

The projects of operations subjected to the visa are accompanied by appropriate supporting documents, certified with regard to reality and legality by the signature of the leaders of specialized compartments that initiate the operation in question and are responsible for their correctness and legality.

\section{Risks specific to the financial field}

The causes leading to the appearance of risks in the financial field are closely related both to the proper organization and activity of the structure and to the activity of the other organizational compartments or structures that the financial structure works with. Some of the most frequent riskgenerating causes can be: 
- frequent changes of the organizational structure, reorganizations, mergers and spin-offs of public institutions, as welll as personnel fluctuations;

- poor organization of the specialized compartments certifying operations to reality, legality and regularity;

- non-identification of the sensitive operations and targeting operations that prove to be ineffective;

- frequent changes of legislation;

- lack of norms, guidelines and detailed procedures for conducting operations, optimizing the flow of documents and precisely defining the responsibilities of specialty departments and staff working in them.

At public institutions by the secretary of the Commission responsible for monitoring, coordination and methodological guidance of the implementation and development of their systems of internal managerial control the Register of risks and the program of development of internal managerial control is drawn up on the basis of the propositions given by the heads of microstructures. The command of the institution approves of these two projects and oversees their implementation and development.

Risk management involves running the following steps [4], irrespective of the domain of activity:

- identification of general and specific objectives having a decisive role in completing the mission;

- establishing the main activities necessary for accomplishing the identified general and specific objectives;

- identification of major risks that can affect the accomplishment of general and specific objectives;

- evaluation of identified risks;

- $\quad$ establishing the measures for managing risks and for implementing them;

- analyzing the stage of implementation of measures of risk management;

- reevaluation of the process of risk management.
The implementation of risk management is a process that involves the effort both of the command and of the whole personnel of an organization, consisting of:

6.1. Identification of risks

The existence of a system of clearly defined objectives within the structure represents the essential premise for identifying and defining risks. Risks are identified and defined in relation to the objectives whose achievement is affected by the appearance of risks.

The identification of risks is achieved by formulating the answer to the following question: Which would be the consequences of not carrying out or of carrying this activity/task inadequately?

\subsection{Evaluation of risks}

Risk assessment involves assessing the probability of risks materializing and their impact on objectives if they materialize. The risk assessment steps are:

6.2.1. assessing the likelihood of materialization of the identified risk;

6.2.2. assessing the impact on objectives if risks materialize;

6.2.3. assessing the exposure to risk.

6.3. Establishing tolerance to risk

3.1. Risk tolerance is the "amount" of risk a structure can tolerate or is willing to be exposed to at a certain moment.

3.2. Establishing the risk tolerance capping consists in putting in a steady relationship the cost for controlling risks with the cost of exposure where the risk would materialize.

6.4. The strategy for risk mitigation controlling risks (response to risk)

a. Once the risks have been identified and evaluated and the tolerance limits have been defined, the type of response to risk is determined for each separate risk by implementing the following strategies:

- Acceptance - involves tolerating risks or not taking measures of control or intervention;

- Avoidance - involves eliminating the activities that generate risks; 
- Permanent monitoring - involves keeping risk under permanent supervision and operating when the probability of risk is increased;

- Transferring risks - involves assigning the risk to a third specialized party, on the basis of contract or insurance, leading to lowering the exposure of the structure to risk;

- Treating risks - means acting through measures to mitigate the likelihood and impact by using tools for internal/managerial control.

b. The internal/managerial control instruments are the set of measures taken to mitigate risks and are classified into six groups, as follows:

- objectives

- means

- information System

- organization

- procedures

- $\quad$ supervision and control.
6.5. The reviewing and reporting of risks involves monitoring the modification of risks as a result of the implementation of internal managerial control tools and of the modification of the circumstances of risk occurrence.

\section{Conclusions}

From this presentation one can assess the relationship of mutual interconnectedness of all forms of control used in the Romanian system of control and management of public funds, which could not work or would work with great difficulty and deficiency without each other. This hypothesis leads to the need for a management control integrator, whereby all control forms join in and work together in order to achieve the desired effect, namely the efficiency and effectiveness of public funds.

\section{References}

[1] The Ministry of Finance, Strategy of development of internal public financial control in Romania for the 2014-2016 period, January 2014, Bucharest, p. 4

[2] The Parliament Of Romania , Law no. 672/2002 regarding internal public audit, republished, with subsequent amendments, available at: http://discutii.mfinante.ro/static/10/Mfp/audit/lege672_mo856_en.pdf

[3] Romanian Government, Ordinance no. $1 \overline{1} 9$ of 31 August 1999 $\left({ }^{* *}\right.$ republished $\left.{ }^{* *}\right)\left({ }^{*}\right.$ updated $\left.{ }^{*}\right)$ regarding internal control and preventive financial control, art. 6 , available at: http://lege5.ro/Gratuit/ge2daojzgeyq/ordonanta-de-urgentanr-3-2017-pentru-modificarea-si-completarea-legii-nr-227-2015-privind-codul-fiscal

[4] The Ministry of Defence, Methodological norms regarding the system of internal/managerial control, Art. 28 , M. Of Romania in force since 18.07.2016 